Brit. J. industr. Med., 1954, 11, 175.

\title{
A REPORT ON 235 CASES OF ERYSIPELOID IN ABERDEEN
}

\author{
BY \\ D. M. PROCTOR and I. M. RICHARDSON \\ From Aberdeen Royal Infirmary and the Department of Social Medicine, Aberdeen
}

(RECEIVED FOR PUBLICATION FEBRUARY 10, 1954)

For some time it had been thought locally that the incidence of erysipeloid of Rosenbach among fish workers was much higher in Aberdeen than elsewhere. For this reason we began a systematic study of the disorder, and our findings over the period June 1, 1952, to September 30, 1953, are presented in this paper.

Doctors generally are not familiar with the lesion known as erysipeloid. Because of its strong occupational association it is well known in localities where there is a risk of infection and, at least in Aberdeen, the skin picture is so easily recognized that fish workers sometimes make their own correct diagnosis of "fish hand" or " fish poisoning". Price and Bennett (1951) reporting on 51 cases, stated that "casualty officers working near meat and fish markets, slaughter-houses, and hotel districts, are quite familiar with the disease and regard it as being by no means uncommon".

Because the clinical picture has been adequately described by many authors only a brief description is given here. The infection first appears as a reddish-blue swelling on the finger or hand, varying in size from 1 to 10 sq. $\mathrm{cm}$.; the edge is raised, well demarcated, and slowly advances. The patient feels a burning, itching pain at the site and often there is a sensation of tightness in the inflamed area. Some stiffness and slight pain are common in the interphalangeal joints near the lesion.

In almost all cases the occupation of the patient is a useful guide to diagnosis. The infecting organism is a strain of Erysipelothrix rhusiopathiae, the causal organism of swine erysipelas, and though the natural history of erysipelothrix is uncertain, it is widely distributed in nature. The source of infection in man is invariably animal or vegetable matter, and the occupations commonly associated are those in which contact with fish, meat, or poultry is entailed ; thus fish workers, slaughtermen, butchers, cooks, and housewives have been the commonest reported sufferers (Klauder, 1938 ; King, 1946 ; Price and
Bennett, 1951). In a very high proportion of patients there is a history of injury - a prick from fish scale or bone, a knife cut or other minor breach of the skinfollowed a few days later by the typical appearance of the infection. After one to three weeks the lesion disappears spontaneously. It is essentially a localized infection, general symptoms being unusual and complications rare. Suppuration does not occur and surgical interference is unnecessary.

Diagnostic biopsy has been performed, but Price and Bennett (1951) found that the proportion of positive cultures was not high enough to make the procedure of great value in diagnosis. We agree with Goodwin (1950) that "In view of the ease in diagnosing the condition clinically, biopsy of the lesion is not justifiable".

A striking feature of erysipeloid is its seasonal incidence. Numerous writers have noted the increased frequency of cases in summer and early autumn and its virtual disappearance in winter and spring.

\section{The Aberdeen Cases}

The casualty department of Aberdeen Royal Infirmary is situated in the city centre about one mile from the harbour where fish are landed; near the market lie about 200 separate "fish houses" where the fresh fish are prepared for sale by various processes. About 2,500 workers are employed in market and fish premises; the proximity of the casualty department to the industry has for many years made it convenient for fish workers to attend there for treatment of hand injuries and infections. Our 235 cases were all observed in the casualty department by one of us (D. M. P.) who is familiar with the condition, and though biopsy has not been performed we are confident that only genuine cases have been included in the study.

Between June 1 and December 31, 1952, 71 cases were observed; we cannot be certain that all cases of erysipeloid attending casualty in 1952 were 
recorded since it took some time to ensure that every patient with the disease was referred to the senior casualty officer. From January 1 to September 30, 1953, 164 cases were observed ; this higher incidence is at least in part due to better methods of detection and we are convinced that it is a true indication of the frequency of the disease as seen in the casualty department.

\section{Clinical Features}

Seasonal Incidence.-Table 1 shows the monthly distribution of the 235 cases.

TABLE 1

NO. OF CASES IN EACH MONTH FROM JUNE, 1952, TO SEPTEMBER, 1953

\begin{tabular}{|c|c|c|c|c|c|c|c|c|c|c|c|c|c|c|}
\hline Month & & $\mathbf{J}$ & $\mathbf{F}$ & $\mathbf{M}$ & A & $\mathbf{M}$ & $\mathbf{J}$ & $\mathbf{J}$ & A & $\mathbf{S}$ & 0 & $\mathbf{N}$ & D & Totals \\
\hline \multirow{2}{*}{$\begin{array}{l}\text { No. of } \\
\text { cases }\end{array}$} & 1952 & & & & & & 4 & 20 & 18 & 13 & 6 & 6 & 4 & 71 \\
\hline & 1953 & 0 & 0 & 1 & 0 & 1 & 9 & 84 & 42 & 27 & & & & 164 \\
\hline
\end{tabular}

The expected seasonal variation is well revealed but we have carried the study of this association a step further. The Meteorological Office at Dyce Airport on the outskirts of the city provided us with hourly air temperature readings (dry bulb) from which we computed mean weekly temperatures for the relevant periods in 1952 and 1953 ; the association between temperature and the incidence of erysipeloid is shown in Table 2 and Fig. 1.

There is a significant correlation between the two variables; it appears that in some way the two are connected but we wish to emphasize that the data do not reveal the nature of the relationship.

Occupational Factors.Table 3 sets out the occupational distribution of the 235 cases.

Two hundred and twentysix $(96 \%)$ of our cases were in some way connected with the fish trade. We are aware that patients in other occupations where erysipeloid is uncommon would probably be seen by their family doctor and therefore our series must have some occupational bias towards fish workers. But
TABLE 2

FREQUENCY DISTRIBUTION OF WEEKLY CASE INCIDENCE BY MEAN WEEKLY TEMPERATURE

\begin{tabular}{|c|c|c|}
\hline $\begin{array}{c}\text { Mean } \\
\text { Weekly } \\
\text { Tem- } \\
\text { perature } \\
\left({ }^{\circ} \mathrm{F} .\right)\end{array}$ & $\begin{array}{c}\text { Number of Weeks with Number of } \\
\text { Cases in Each Week } \\
{[()=\text { one week }]}\end{array}$ & $\begin{array}{c}\text { Mean Weekly } \\
\text { Incidence } \\
\left(\frac{\text { No. of Cases }}{\text { No. of Weeks }}\right)\end{array}$ \\
\hline 34.4 & $(0)(0)(0)$ & 0 \\
\hline $\begin{array}{l}34 \cdot 5- \\
36 \cdot 5- \\
38 \cdot 5- \\
40 \cdot 5- \\
42 \cdot 5- \\
44 \cdot 5- \\
46 \cdot 5- \\
48 \cdot 5- \\
50 \cdot 5- \\
52 \cdot 5- \\
54 \cdot 5- \\
56 \cdot 5- \\
58 \cdot 5 \\
\text { and over }\end{array}$ & $\begin{array}{l}\text { (1) (1) (2) } \\
(1)(0)(0)(0) \\
(1)(0)(0)(0)(0)(0) \\
(4)(0)(1)(0)(0) \\
(2)(0)(0) \\
(5)(2)(0)(0)(0)(0) \\
(3)(2)(2)(0)(0) \\
(1)(0)(2)(1)(0)(0)(2) \\
(0)(0) \\
(1)(10)(0) \\
(5)(6)(7)(7)(14)(14)(24)(18)(5)(5) \\
(1)(2)(6)(1)(3)(3)(4)(14)(9)(9)(12) \\
(3)(19)\end{array}$ & $\begin{array}{r}1 \cdot 33 \\
.25 \\
.17 \\
1 \cdot 0 \\
.67 \\
1 \cdot 17 \\
1 \cdot 40 \\
.86 \\
0 \\
3 \cdot 67 \\
10 \cdot 50 \\
5 \cdot 82 \\
11 \cdot 0\end{array}$ \\
\hline
\end{tabular}

Correlation coefficients : $1952 \mathrm{r}=0.48 \quad 1953 \mathrm{r}=0.67$

$\begin{array}{rr}\text { S.E. }=0.14 & \text { S.E. }=0.09 \\ \text { P }<0.01 & \text { P }<0.001\end{array}$

their preponderance in Table 3 is so striking that even without a measure of the numbers exposed to risk of infection we feel it safe to conclude that, in Aberdeen, fish workers are the commonest sufferers.

Fish processers are in frequent and intimate contact with fish ; these are the people who actually handle the fish whereas porters and lorry drivers

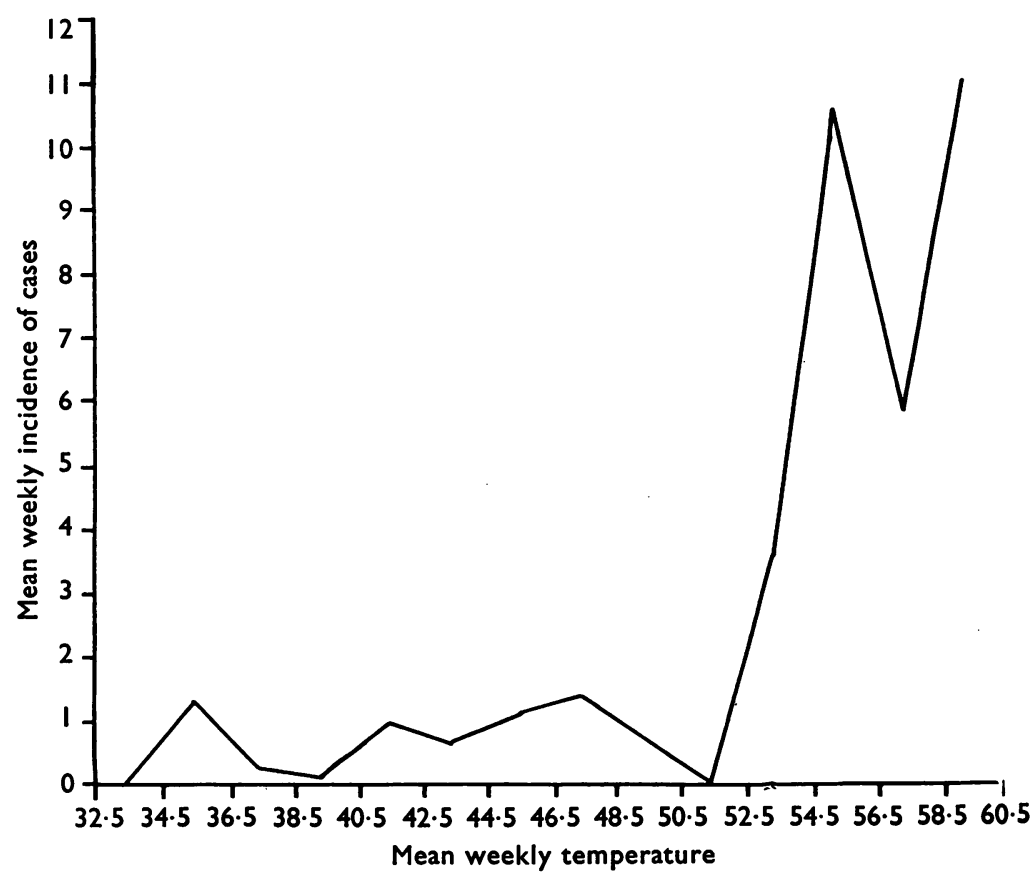

FIG. 1.-Association of temperature with erysipeloid case frequency. 
TABLE 3

OCCUPATIONAL DISTRIBUTION OF CASES

\begin{tabular}{|c|c|c|c|c|c|}
\hline \multicolumn{5}{|c|}{ Occupation } & $\frac{\text { No. of Cases }}{152}$ \\
\hline $\begin{array}{l}\text { Fish processers } \\
\text { Fish porters } \\
\text { Fish-lorry drivers } \\
\text { Fish-box repairers } \\
\text { Fish-meal workers } \\
\text { Fishmongers ... } \\
\text { Salmon overseer } \\
\text { Trawlermen } \\
\text { Fish-office clerk } \\
\text { Fish-lorry mechanic } \\
\text { Labourers }\end{array}$ & $\begin{array}{l}\cdots \\
\cdots \\
\cdots \\
\cdots \\
\cdots \\
\cdots \\
\cdots \\
\cdots \\
\cdots\end{array}$ & $\begin{array}{l}\cdots \\
\cdots \\
\cdots \\
\cdots \\
\cdots \\
\cdots \\
\cdots \\
\cdots \\
\cdots\end{array}$ & $\begin{array}{l}\cdots \\
\cdots \\
\cdots \\
\cdots \\
\cdots \\
\cdots \\
\cdots \\
\cdots \\
\cdots\end{array}$ & \begin{tabular}{l|l} 
& \\
$\cdots$ & \\
$\cdots$ & \\
$\cdots$ & \\
$\cdots$ & \\
$\cdots$ & \\
$\cdots$ & \\
$\cdots$ & \\
$\cdots$ &
\end{tabular} & $\begin{array}{r}152 \\
29 \\
10 \\
12 \\
12 \\
4 \\
1 \\
2 \\
1 \\
1 \\
2\end{array}$ \\
\hline Total in fish trade & & $\cdots$ & $\cdots$ & $\cdots$ & 226 \\
\hline $\begin{array}{l}\text { Butchers } \\
\text { Housewife } \\
\text { Car polisher } \\
\text { Pig slaughterer } \\
\text { Bus cleaner } \\
\text { Poultry cleaner }\end{array}$ & $\begin{array}{l}\cdots \\
\cdots \\
\cdots \\
\cdots \\
\cdots\end{array}$ & $\begin{array}{l}\cdots \\
\cdots \\
\cdots \\
\cdots \\
\cdots\end{array}$ & $\begin{array}{l}\ldots \\
\cdots \\
\cdots \\
\cdots \\
\cdots\end{array}$ & \begin{tabular}{l|}
$\cdots$ \\
$\cdots$ \\
$\cdots$ \\
$\cdots$
\end{tabular} & $\begin{array}{l}4 \\
1 \\
1 \\
1 \\
1 \\
1\end{array}$ \\
\hline
\end{tabular}

mainly handle boxes of fish. Fish boxes, whether full or empty, appeared to be a common source of infection and we have obtained strong evidence of this in several cases where the only known recent exposure to infection was through a fish box. For example, the car polisher who worked near the fish market had, on one occasion only, assisted a lorry driver to hoist two closed boxes of fish on to his vehicle and three days later developed a typical lesion at the site of contact. The source of infection was less certain in the mechanic who maintained fish lorries to which slime often adheres and in the man who cleaned the interior of buses used by fish workers on their way to and from work.

In every one of the 235 cases there was either a probable or a possible source of infection associated with the individual's work and it is therefore correct to label erysipeloid an occupational disease.

The Role of Trauma.-One hundred and seventyeight patients $(75 \%)$ had sustained an injury a few days before the lesion appeared. A further $20(9 \%)$ were of the opinion that minor trauma was responsible but could not state definitely when it had been received. Fish workers are constantly receiving small wounds of the skin from fins, teeth, knives, and machines or from rough parts of fish boxes, and it is therefore not surprising that some patients could not recall precisely when they were injured.

The site of the infection is of interest in relation to the areas of skin especially exposed to risk of injury. Sixty per cent. of the lesions were found on the left hand and the most frequent sites were on a band stretching across the palmar aspect of the middle phalanx of the fingers to an area on the thenar eminence ; these are the parts of the hand in most frequent and close contact with the fish as it is held in the left hand for treatment with the knife held in the right; thus fish processers are more liable to injure the left hand and this we believe to be the explanation of the significantly greater incidence on that hand.

Incubation Period.-This has been estimated from the 160 case histories in which the dates of specific trauma and onset of symptoms were known. Table 4 shows the frequency distribution.

TABLE 4

ESTIMATED INCUBATION PERIOD

\begin{tabular}{cc}
\hline Incubation Period (No. of Days) & No. of Cases \\
\hline $1-3$ & 106 \\
$4-7$ & 39 \\
$8-14$ & 8 \\
$15+$ & 7 \\
\hline
\end{tabular}

In two-thirds of these cases an incubation period of less than four days was recorded; in a few patients the appearance of the lesion seemed to have been delayed for one to three weeks after the injury blamed but it is quite feasible that infection entered through a later but unobserved breach of the skin. Our material certainly suggests that the incubation period is usually very brief.

General Symptoms. - Slight malaise was not uncommon but pronounced general symptoms were absent. In 39 cases (16\%) lymphangitis and or axillary lymphadenitis were detected, a rather higher incidence than that reported by King (1946) but not unexpected in view of the experience of Klauder, Righter, and Harkins (1926) who found that these features were commonly associated with erysipeloid among certain fish handlers in New Jersey.

Local Signs and Effects.-The skin lesion of erysipeloid is remarkably constant in appearance and progression. It begins with sensations of heat, itch, or burning and later becomes painful, the pain being of a " prickly " character and accompanied by tenderness and tightness in the affected area. At first the skin shows a pink blush which rapidly changes through red to reddish-blue ; this violaceous tint is highly characteristic (Figs. 2 and 3). As the lesion develops the periphery spreads and shows a marked tendency to affect other digits. Slight pain and stiffness in the adjacent finger joints are common and there is a notable absence of purulence. But it should be noted that a pyogenic infection may coincide as it did in two of our cases. The infection spreads for a few days, the advancing edge being slightly raised, whilst the centre fades and slight desquamation appears. 

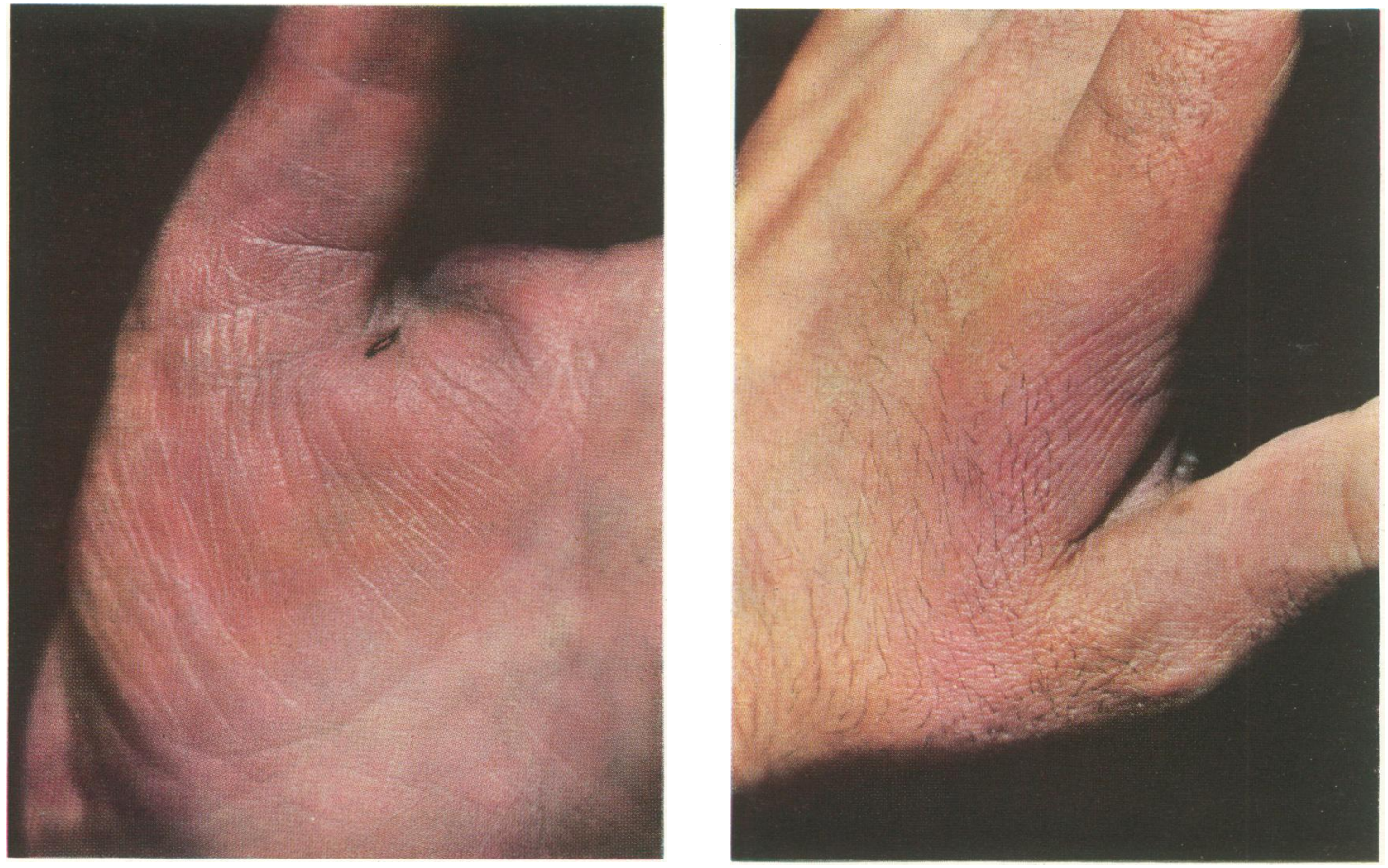

FIGs. 2 and 3.-Erysipeloid of Rosenbach following a cut on a fish box.

In our series all the lesions were on the hand and occasionally two separate patches were seen, especially on the fingers. We have tried to estimate the duration of the lesion by noting the time taken for complete disappearance; our data are necessarily incomplete because many patients discharged themselves, but the average duration of attendance was seven days with a range from two to 27 days. A few lesions were resistant to treatment, tending to relapse once or even twice despite daily attention and in these patients the disability was correspondingly greater. It is important to stress that, though the local disability is usually slight, a bandaged finger can be a real handicap in an occupation requiring much dexterity, and since so much of the work has to be done in moisture, we have often found it necessary to advise the patient to go off work unless a dry alternative job could be obtained. In this regard the disorder is a disabling one and of considerable socio-economic importance. Twenty-three per cent. of our patients admitted a previous attack thus suggesting that immunity following one attack is of a low order.

Treatment.-There has been some controversy about the best method of treating erysipeloid. We have made no attempt to assess statistically the therapeutic value of any remedy; the infection is self-limiting and without a carefully planned and executed clinical trial our views are no advance on those already published. For many years it has been the routine practice in Aberdeen to dress the lesion with $10 \%$ ichthyol in glycerine but since penicillin became generally available an increasing number of patients have received it by intramuscular injection.

The findings of Barber, Nellen, and Zoob (1946) and of Sneath, Abbott, and Cunliffe (1951) suggest that penicillin should be an effective therapeutic agent in erysipeloid; Price and Bennett (1951), though unable to draw definite conclusions from their small series, appeared to obtain favourable responses to parenteral penicillin. It is certainly our impression that penicillin is a useful addition to the usual local treatment but on this point we hope in future to produce more precise evidence.

\section{Discussion}

Our main purpose in presenting this paper is twofold. First we wish to draw attention to an infection which though common is unfamiliar to many doctors; because of its occupational and therefore local associations the medical student may never see it and may misdiagnose it in his later practice. In Aberdeen the lesion is common and well 
known but elsewhere its incidence may be sporadic, its connexion with work missed, and the sufferer denied his right to injury benefit.

Secondly we have attempted to throw some light on its aetiology. The natural history of Erysipelothrix rhisiopathiae is obscure but our data strongly suggest that its biological activity is in some way related to atmospheric temperature ; the disease in man virtually disappears in the colder months of the year and a warm spell is usually followed by a sharp rise in incidence. We have not been able to compute a rate per 1,000 fish workers because it is not known accurately how many people in different occupational groups are exposed to risk, but we believe that even allowing for the fluctuations in labour force there is no reasonable doubt that the correlation with temperature is a real one.

One of our colleagues, Dr. Stuart of Aberdeen University Department of Bacteriology, is studying the biology of the erysipelothrix and we are authorized to state that she has been unable to demonstrate the organism in sea-fresh fish landed and preserved under aseptic conditions ; once fish caught in the normal way have reached the market the organism is isolated with ease during the "erysipeloid season ". Our own observations on the role of contact with fish boxes suggest that fish slime and scales may harbour infection, an opinion that has been expressed by Klauder and others (1926). This author and his associates reported "about 1,000" cases of erysipeloid among commercial fishermen on the eastern seaboard of America and concluded that among such men the disease took a more severe form ; in a further paper (Klauder, 1938) on erysipeloid as an occupational disease, it is stated that " in our studies infection was more severe when contracted from a fish source". Klauder observed that the infection was less frequent and milder among wholesale and retail handlers of fish in markets and certainly we have in our series encountered no examples of the more severe type described by him.

During our investigation we were aware that trawlermen who might be infected with erysipelothrix would not attend the casualty department ; for 50 years the men of trawlers based in Aberdeen have had their own clinic down in the harbour area. This clinic is owned and managed by the men themselves and exists to treat and compensate (by contributory insurance) injuries received while at sea ; through the kind cooperation of Dr. John
Leiper and Sister W. D. Clark, medical officer and nurse at the clinic, we have been notified of five definite cases of erysipeloid among trawlermen in the period January-October, 1953. The number of men exposed to risk is about 2,200 and we can therefore state with confidence that the incidence among trawlermen is far lower than among fish workers on land ; yet aboard ship on the way to port the trawler crews gut the fish before packing them in ice and would, it seems, be exposed to intimate risk of infection. This finding is of interest in view of the above observations by our colleague Dr. Stuart.

Further elucidation of the aetiology of human erysipeloid depends on epidemiological studies. In particular it is desirable that sources of infection should be accurately traced, for until these are defined, preventive measures must remain uncertain. If the opinion expressed in our introduction, that the infection is more common relatively in Aberdeen, is correct, data from other fishing ports might contribute towards an understanding of this minor but by no means unimportant condition.

\section{Summary}

A series of 235 cases of erysipeloid of Rosenbach is reported. There is a significant correlation between incidence of the disorder and atmospheric temperature.

In Aberdeen fish workers are the commonest sufferers.

The role of injury is discussed and it is shown clinically that fish boxes may harbour infection.

The amount of disability caused makes erysipeloid a condition of socio-economic importance and one which merits intensive epidemiological study.

We are indebted to the Meteorological Officer at Dyce Airport for the temperature readings, to Dr. F. H. C. Marriott for statistical assistance, and to Dr. Stuart, our colleague in bacteriology, for her interest and information. The colour photographs were taken by Mr. R. G. Drummond of the University photographic department. We gladly acknowledge the help given by the staff of the casualty department of Aberdeen Royal Infirmary.

\section{REFERENCES}

Barber, M., Nellen, M., and Zoob, M. (1946). Lancet, 1, 125.

Goodwin, M. A. (1950). Brit. med. J., 1, 765.

King, P. F. (1946). Lancet, 2, 196.

Klauder, J. V. (1938). J. Amer. med. Ass. 111, 1345. Righter, L. L., and Harkins, M. J. (1926). Arch. Derm. Syph., Chicago, 14, 662 .

Price, J. E. L., and Bennett W. E. J. (1951) Brit, med, J., 2, 1060 Sneath, P. H. A., Abbott, J. D., and Cunliffe, A. C. (1951). Ibid., 2, 1063. 